\title{
Induced tooth movement: Standardization of terms to describe the effects of forces on the periodontal ligament Compression/Traction instead of Pressure/Tension
}

\author{
Alberto Consolaro ${ }^{1}$
}

There is no reason for Dentistry to use different terms for phenomena defined in Physics, the specific field in which concepts associated with forces are established and adapted. In place of pressure/tension, the compression/traction pair should be used. This study defines each one of these terms and justifies their use. Our contemporary world demands standardized criteria, methods, measures, concepts and terms to ensure that study protocols, results and applications are used in the same way in any country or area of human action.

Keywords: Tooth movement. Orthodontic movement. Pressure. Tension. Traction. Compression.

\section{INDUCED TOOTH MOVEMENT AND ORTHODONTIC MOVEMENT}

The first microscopic examination of bone after induced tooth movement was conducted in dogs by Carl Sandstedt ${ }^{79}$ in 1901. His study reported on phenomena still currently observed ${ }^{4,6}$ and even described remote bone resorption. His studies, first published in Swedish, were translated into English as "some contribution for the orthodontic movement theory". Later he reported his results in three studies, ${ }^{8,9}$ summarized and translated into German in 1904 and 1905. In human tissues, the first microscopic observation was reported by Herzberg in $1932 .{ }^{3}$
${ }^{1}$ Head Professor, School of Dentistry of Bauru (FOB) and Graduate Program of School of Dentistry of Ribeirão Preto (FORP), University of São Paulo (USP), Brazil.

\footnotetext{
How to cite this article: Consolaro A. Induced tooth movement: Standardization of terms to describe the effects of forces on the periodontal ligament - Compression/ Traction instead of Pressure/Tension. Dental Press J Orthod. 2012 Mar-Apr;17(2):27-9.

Submitted: March 26, 2012 - Revised and accepted: March 31, 2012.

» The author reports no commercial, proprietary, or financial interest in the products or companies described in this article.

Contact address: Alberto Consolaro

E-mail: consolaro@uol.com.br
} 
The mechanical forces applied to teeth do not result in mechanical movement only: They also produce biological stimuli capable of promoting desirable tissue reactions to achieve a stable and long-lasting change in tooth position. Similar suggestions have been made for decades, particularly by Noyes, ${ }^{5}$ in 1942, and Baumrind and Buck, ${ }^{1}$ in 1970 . This process received the name of mechanotransduction: A physical stimulus is translated into a biological event represented by the set of changes induced in cells and tissues. Mechanotransduction may be expressed as the set of biological effects in response to the break of tensegrity, or physical balance, of the architecture of cells and tissues.

Orthodontic movement is produced using wires, and it is classified as orthodontic if the purpose of tooth movement is to correct esthetic and functional problems of teeth and face. Therefore, orthodontic movement is perceived as a specific tooth movement because it has very specific objectives. Induced tooth movement, by definition, is not physiological, differently from movement due to tooth eruption or tooth displacement due to the action of vectors generated during growth. Induced tooth movement is a movement triggered by other stimuli, external to teeth and bones, usually mechanical, and originated from forces generally released by appliances applied to teeth.

The comparison of the terms orthodontic movement and induced tooth movement suggests that orthodontic movement results from orthodontic treatment and corresponds to an induced tooth movement. Induced tooth movement does not necessarily correspond to orthodontic movement, because its purpose may be different and not defined as orthodontic, that is, to correct dental and maxillofacial changes. In experimental trials with animals, the purpose of tooth movement is to investigate the changes in support tissues of the teeth involved. The most accurate definition for this type of displacement is induced tooth movement even when performed with an appliance commonly used in Orthodontics. The appliance, however, may not be defined as an orthodontic appliance if the precise meaning of the words is respected.

\section{PRESSURE/TENSION: AN IMPORTANT CHANGE INTO COMPRESSION/TRACTION}

For many decades, orthodontic movement and the effects produced by forces on the periodontal ligament and the alveolar process were referred to as areas of pressure and areas of tension in practically all studies, ${ }^{4,6}$ except in rare situations. In the pressure side, the ligament was compressed by the tooth against the alveolar bone and, in the tension side, at the same time, the periodontal ligament was stretched or pulled.

Some authors drew attention to several nuances of concepts and terms common to Physics when attempting to define the characteristics of these areas in the study and understanding of the biology of induced tooth movement. Our contemporary world demands standardized criteria, methods, measures, concepts and terms to ensure that procedures, trials and applications may be used in any country and area of human action.

In the biopathology of orthodontic movement, based on the third edition of the book Dental resorptions in clinical specialties, ${ }^{2}$ we suggested a reorganization of these terms, which describe several biological events, and did so in light of the definitions presented below.

\section{The concept of tension}

Tension identifies a force or system of forces that acts upon a solid body per unit of area and that is capable of producing compression, shearing or traction. In orthodontic movement, the set of forces applied may be called tension all together because they compress the periodontal ligament on one side and pull or stretch it on the other side; that is, it is a system of forces.

\section{The concept of pressure}

In everyday language, pressure may also be synonymous with compression and tension. It may mean the act or effect of pressing, compressing and tightening. It may also be translated as a force applied to a body by other body in contact with it. The use of this term in orthodontic movement may generate confusion for those familiar with the physical concept. Tension is a system that may compress or pull. 


\section{The concept of traction}

Traction is one of the effects that forces may exert on a body when applied within a system called tension. Traction means the act or effect of pulling, dragging and moving. In mechanics, it expresses the situation of a body when under the action of a force that tends to elongate it. In induced tooth movement, this term is more precise to describe what was generally called the tension side.

\section{The concept of compression}

When forces are applied within a tension system, compression is the most appropriate term to describe the act or effect of applying compression. This term indicates an increase of pressure in a physical system due to the action of forces or external agents, such as in orthodontic movement. The term is perfectly consistent with what was previously called the pressure side.

\section{FINAL CONSIDERATIONS}

In our contemporary world, the economic system and the intense and fast exchange of information constantly demands greater uniformity of criteria, methods, measures, concepts and terms. Such uniformity enables the use of protocols, trials and industrial, commercial and clinical applications of research and studies in any country and area of human action. There is no reason for Dentistry to use different concepts for the same phenomena in Physics, the specific field to define and adapt concepts associated with forces. In place of pressure/tension, we suggest the use of the compression/traction pair, a change that will contribute to the required uniformity.

\section{REFERENCES}

1. Baumrind S, Buck D. Rate changes in cell replication and protein synthesis in the periodontal ligament incident to tooth movement. Am J Orthod. 1970 Feb;57(2):109-31.

2. Consolaro A. Reabsorções dentárias nas especialidades clínicas. $3^{\text {rd }}$ ed. Maringá: Dental Press; 2012.

3. Herzberg B. Bone changes incident to orthodontic tooth movement in man. J Am Dent Assoc. 1932;19:1777-8.

4. Meikle MC. The tissue, cellular, and molecular regulation of orthodontic tooth movement: 100 years after Carl Sandstedt. Eur J Orthod. 2006;28(3):221-40.

5. Noyes F. Histology of bone related to orthodontic treatment. Am J Orthod. 1942;28(12):760-9.

Persson M. A $100^{\text {th }}$ anniversary: Sandstedt's experiments on tissue changes during tooth movement. J Orthod. 2005;32(1):27-8.

7. Sandstedt CE. Några bidrag till tandregleringens teori. Stockholm: Kungl Boktryckeriet; Nordstedt \& Söner; 1901

8. Sandstedt C. Einige Beiträge zur Theorie der Zahnregulierung. Nord Tandl Tidskr. 1904;5:236-56; 1905;6:1-25; 6:141-68.

9. Spangberg C. Carl Sandstedt-a biography. Nord Medicinhist Arsb. 1992:159-70. 